\title{
(RE) CONSTRUINDO OS EFEITOS DE SENTIDO DA NOTA DE MIL CRUZEIROS: A CÉDULA DO BARÃO TAMBÉM SE LÊ
}

\author{
Airton Jordani Jardim Filho, \\ PPGDesign/UDESC
}

\section{RESUMO}

O objetivo deste trabalho é realizar a leitura de imagem de uma cédula de mil cruzeiros, lançada em 1977, idealizada por Aloísio Magalhães e que tornou-se referência cultural no Brasil. O artigo utiliza, como base, a proposta de Sandra Ramalho e Oliveira, em seu artigo "Imagem também se lê" (2006) para a leitura de imagens, iniciando pelo escaneamento visual, seguido da desconstrução e elaboração de esquemas visuais; da redefinição dos elementos constitutivos; dos procedimentos relacionais entre os elementos; da reconstrução dos efeitos de sentido; procedendo ao trânsito incansável entre elementos, procedimentos, bloco de elementos, todo e partes, esquema visual e imagem; e, por fim, apresentando os dados de identificação da imagem. Além disso, faz uso de outras referências bibliográficas, não apenas relacionadas a leitura de imagem, mas também ao design visual e sua história no Brasil com o intuito de contextualizar a obra e seu autor.

Palavras-chave: Barão, leitura de imagens, design de cédulas, Aloísio Magalhães, história do design.

\begin{abstract}
This paper aims to do an image reading of a one thousand cruzeiros banknote, launched in 1977, designed by Aloisio Magalhães, which became a cultural reference in Brazil. The article is based on the image reading method by Sandra Ramalho Oliveira, in her article "Imagem também se lê" (2006), starting with the visual scanning, followed by deconstruction and elaboration of visual patterns, the redefinition of the constituent elements; relational procedures between elements; reconstruction of meaning effects; proceeding to the tireless transit between elements, procedures, block elements, whole and parts, visual and image schema, and finally presenting data image identification. Besides, it makes use of other references, related reading not only image but also the visual design and its history in Brazil in order to contextualize the work and its author.
\end{abstract}

Key-words: Baron, image reading, banknote design, Aloísio Magalhães, design history. 


\section{APRESENTAÇÃO}

Este artigo foi escrito como exigência parcial de uma disciplina introdutória à Semiótica, para o Programa de Pós-Graduação em Design (PPGDesign), da Universidade do Estado de Santa Catarina. Seu objetivo é fazer a leitura de um texto visual bastante peculiar: uma nota de dinheiro, mais precisamente, uma cédula de mil cruzeiros, produzida na década de 1970, no Brasil.

Peculiar, por carregar consigo diversas e variadas funções, efeitos de sentido e qualidades sensíveis. Conhecida como a "nota do Barão", esta cédula marcou época e serve ainda hoje de referência quando se fala em dinheiro do Brasil. Sua visualidade pode ser objeto de leitura, uma vez que

Toda imagem pode ser considerada um texto e essa é uma reflexão sobre a significação de textos não-verbais. (RAMALHO E OLIVEIRA, 2005, p.89)

Tipicamente transdisciplinar, a produção de cédulas de dinheiro é um trabalho de muitas especificidades que congrega técnicas do design gráfico, mas também da comunicação, da engenharia, da história, da economia e, ainda, das artes visuais (o processo de impressão de uma nota, por exemplo, tradicionalmente contém elementos bastante similares ao processo de impressão de gravuras como o "talho-doce" ou "buril"1). Essa transdisciplinaridade suscita um estudo muito mais aprofundado e que não faz parte do escopo deste texto, mas poderá, futuramente, ser abordado em momento outro.

A leitura deste texto visual seguirá a proposta de RAMALHO E OLIVEIRA (2006, p. 217) para a leitura de imagens, iniciando pelo escaneamento visual, seguido da desconstrução e elaboração de esquemas visuais; da redefinição dos elementos constitutivos; dos procedimentos relacionais entre os elementos; da reconstrução dos efeitos de sentido; procedendo ao trânsito incansável entre elementos, procedimentos, bloco de elementos, todo e partes, esquema visual e imagem; e, por fim, apresentando os dados de identificação da imagem.

\footnotetext{
${ }^{1}$ Gravura a buril: Método de gravura em que a imagem é entalhada diretamente na superfície de uma chapa metálica (geralmente cobre). [...] O método é essencialmente linear, embora se possa obter variação tonal e sombreamento por meio de hachura, linhas paralelas ou texturas compostas de pontos e pequenos talhos. Tipicamente, as gravuras a buril apresentam uma qualidade de precisão austera e metálica, devida em parte à natureza dos materiais e em parte à incisão lenta e calculada das linhas. (CHILVENS, 2001, p. 234)
} 
Os dados de identificação da imagem podem, é claro, consistir no primeiro item a ser objetivado quando de um estudo. Todavia, dados empíricos têm demonstrado que esses dados 'contagiam' a análise, como que tomando do leitor a sua própria capacidade de compreender as formas e cores diante de si. (RAMALHO E OLIVEIRA, 2006, p. 218)

Neste caso, o artigo avançará um pouco mais sobre os dados de identificação e apresentará, por fim, uma breve contextualização histórica da nota, bem como dados relevantes dos autores do projeto, pois tais informações trazem importantes significados ao todo da obra e, por consequência, a este artigo.

\section{A NOTA DE MIL CRUZEIROS, O ESPELHAMENTO DO BARÃO}

Na figura 1 estão reproduzidos o reverso e o anverso de uma nota de dinheiro.
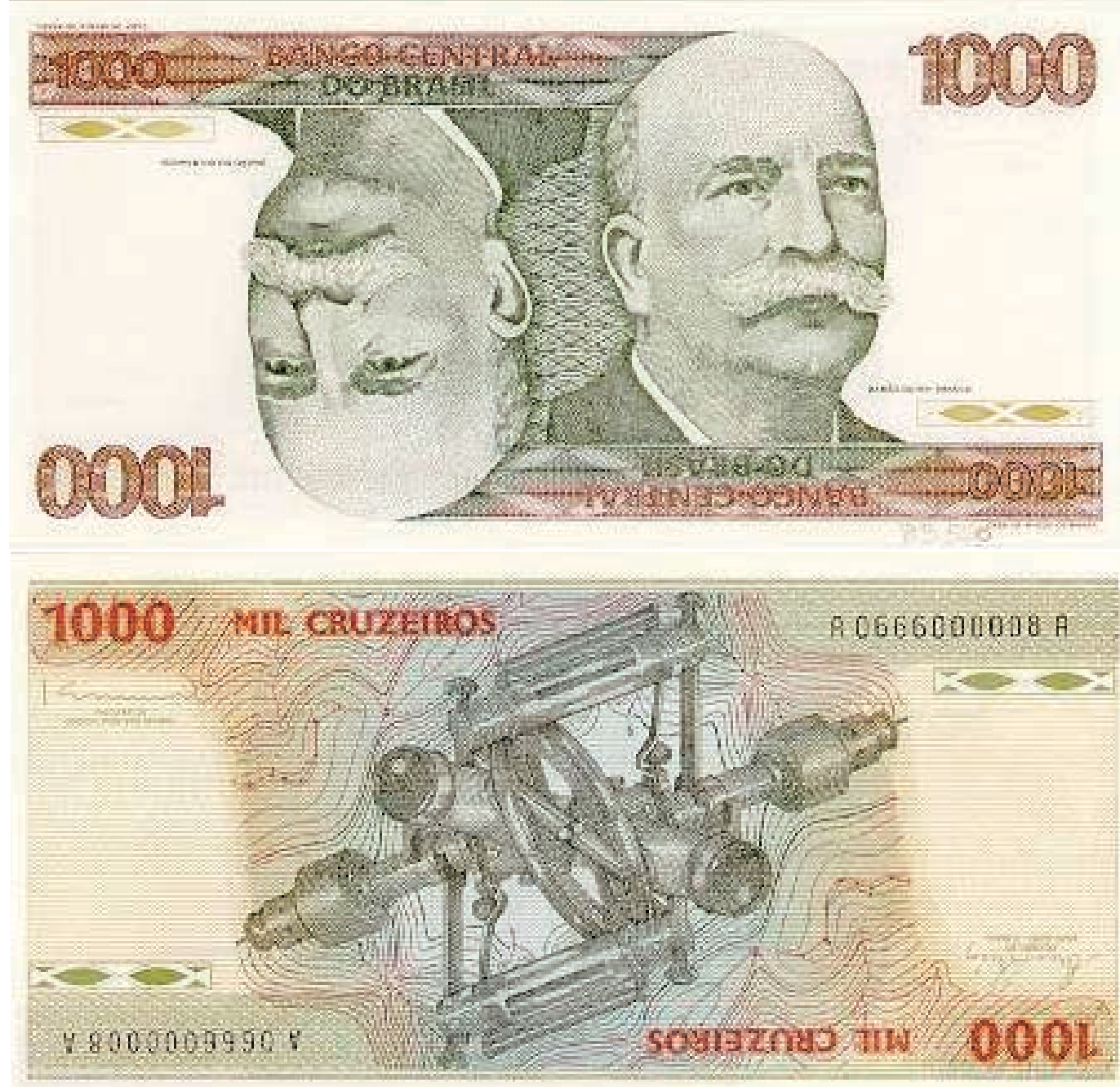

Figura 1: A nota de mil cruzeiros. 
Trata-se, pois, da imagem que será analisada neste trabalho: uma nota de mil cruzeiros, em ambos as suas faces. É importante ressaltar que esta reprodução perde muitas das características originais do objeto. Nesta imagem, por exemplo, a textura tanto do papel quanto daquela criada em virtude do processo de impressão típico de notas de dinheiro - não pode ser reproduzida.

Além disso, a fidelidade da cor não é plena, tampouco se consegue o efeito da nota propriamente dita que, por sua característica de se apresentar em reverso e anverso, jamais exibiria suas faces de forma concomitante (em sua plenitude) na nota original.

\section{ESQUEMAS VISUAIS, LINHAS CONSTRUTIVAS}

Ao agrupar-se os elementos gráficos constitutivos do texto imagético, é perceptível, de forma clara, a distribuição harmônica dos elementos no suporte da nota

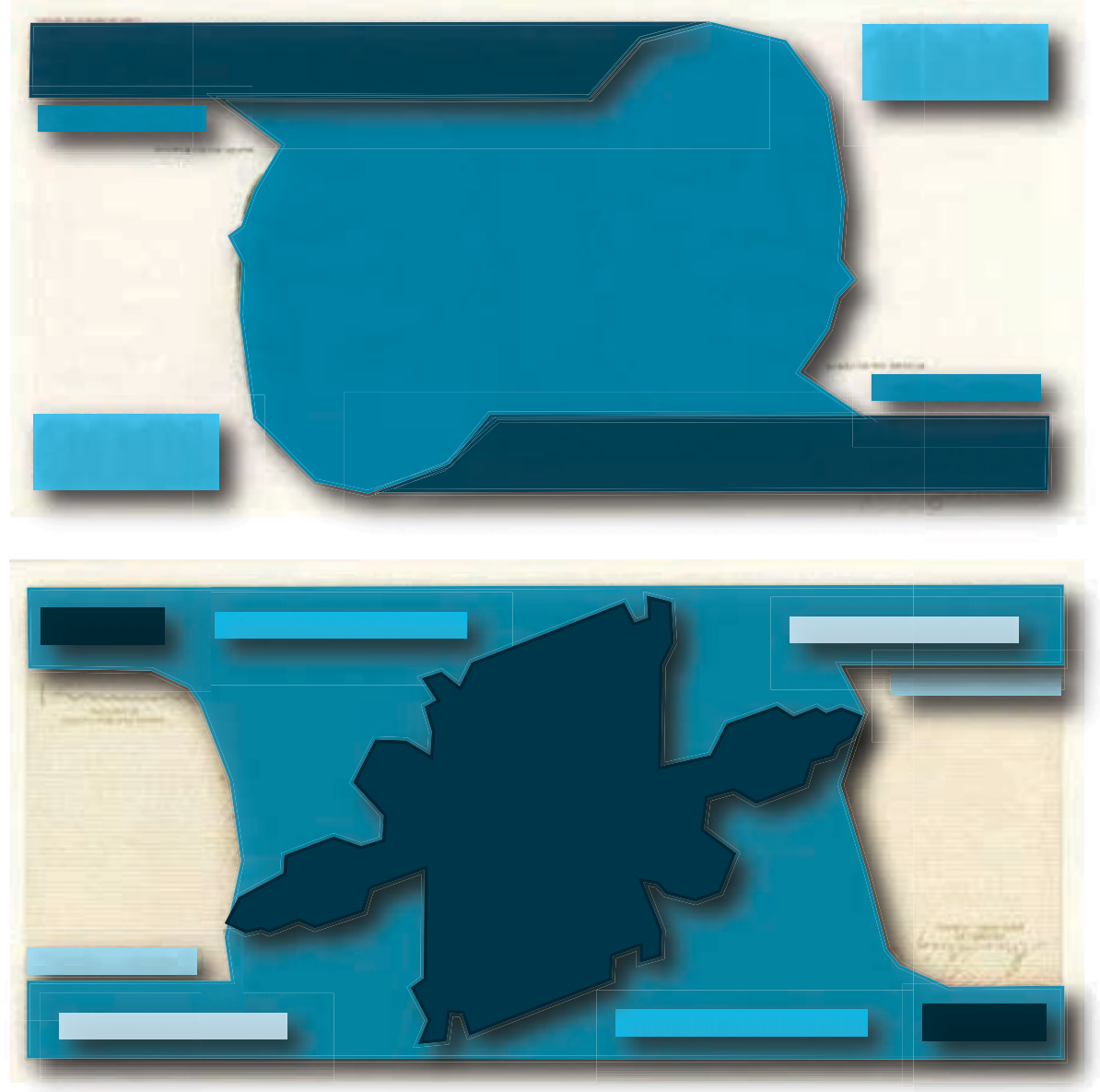

Figura 2: Agrupamento de elementos gráficos constitutivos. 
(neste caso, o papel). Como cada face da nota é divida em dois eixos - horizontal e vertical - e esta distribuição é utilizada como meio para atingir o objetivo, que é um layout baseado em eixo simétrico vertical central e um segundo eixo, horizontal.

A nota, tem ainda, algumas áreas vazias, sem elementos gráficos visíveis, localizadas nas extremidades - esquerda e direita - da cédula. Estas áreas vazias são, na verdade, parte fundamental do sistema de segurança desta nota. Se vista contra a luz, a partir de qualquer uma de suas faces, é possível enxergar nesses espaços, uma marca d'água com a mesma efígie impressa no anverso da nota.
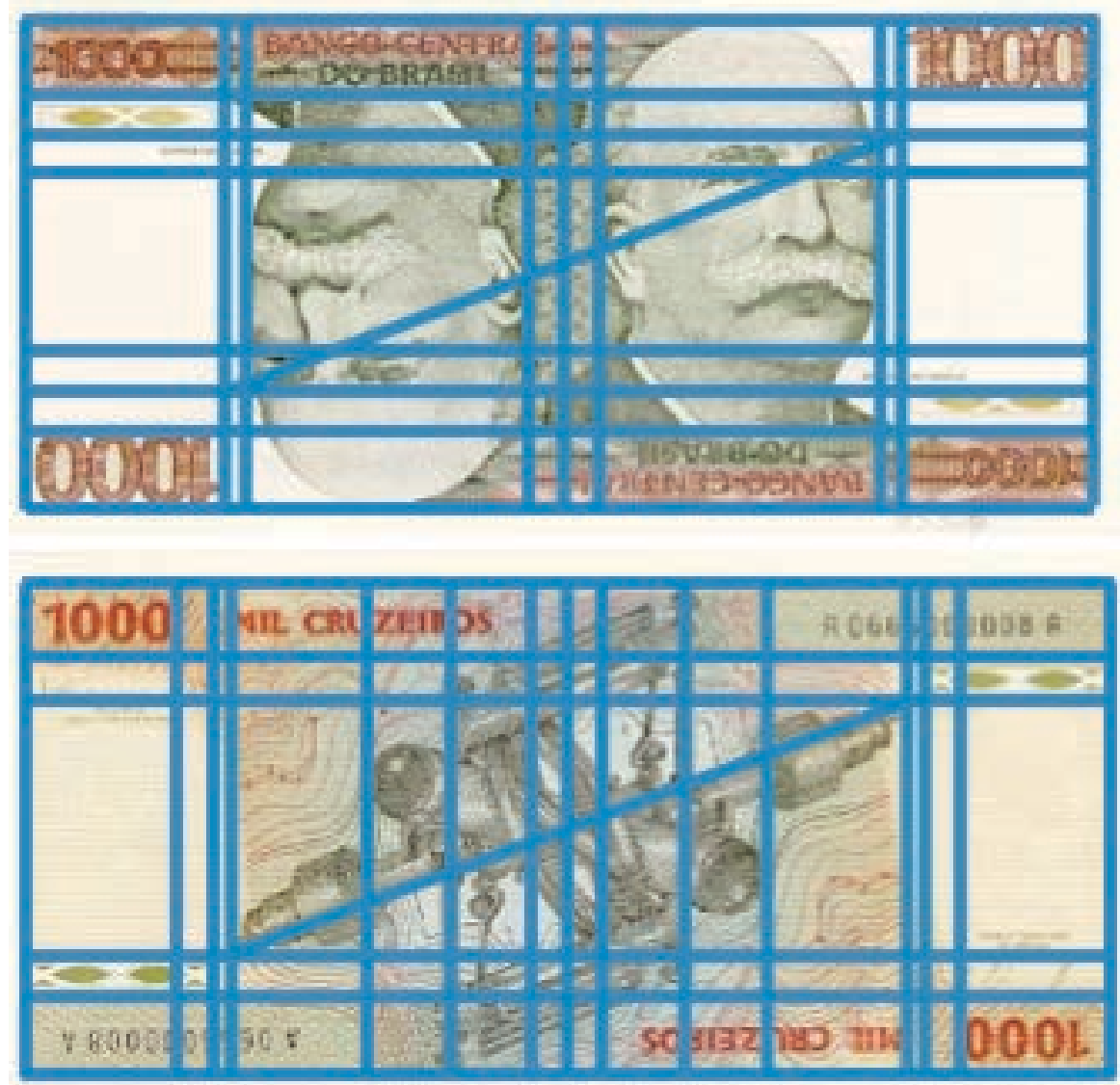

Figura 3: Esquemas visuais através de linhas construtivas.

Além das áreas vazias, é relevante apontar a grande mancha causada pelo acúmulo de elementos, localizada no centro do cédula, em ambas as faces. Tal mancha está emoldurada por elementos horizontais, nas extremidades superior e inferior da cédula, sendo que em seu reverso, em função do uso de linhas que compõem a textura do fundo, a mancha interage mais com suas molduras das extremidades, tornando a mancha mais compacta e maior. Até mesmo os elementos textuais acabam tendo uma 
função visual-compositiva importantíssima, pois sua textura, cor e localização são fundamentais para a composição visual.

Depois de identificar a estrutura básica da imagem, RAMALHO E OLIVEIRA (2006, p. 213) sugere que se parta para a descoberta dos chamados esquemas visuais. Segundo a autora, "a função desses esquemas é a de subtrair as cores e os detalhes, chamando a atenção do olhar do enunciatário para as formas, em detrimento das cores, sempre sedutoras, bem como para as formas macro das figuras, em si".

Ressalta-se aqui a aglutinação de formas no centro e nas extremidades superiores e inferiores da nota. Isso faz com que o peso visual da imagem concentrese no centro da cédula.

Ao analisar o esquema visual criado a partir das linhas construtivas, percebe-se que os elementos da nota podem, quase que totalmente, serem encaixados dentro de um grid de linhas horizontais e verticais, tanto no anverso, quanto no reverso. A única exceção para isso é, justamente, o elemento principal de cada face. Em ambas é possível traçar uma linha diagonal ascendente.

No caso do anverso, temos essa linha diagonal passando pela linha dos olhos das efígies; no caso do reverso, temos uma figura de um aparelho, igualmente cortado por uma linha diagonal ascendente, que aponta, em suas extremidades para um retângulo com figuras elípticas, que se repete, de forma muito semelhante, no reverso (diferindo apenas na cor: no reverso ele é verde). Tal retângulo, aparentemente, compõe um dos elementos de segurança da nota, pois colocada contra luz, encaixa ambos os retângulos encaixam-se perfeitamente.

\section{PROCEDIMENTOS RELACIONAIS ENTRE OS ELEMENTOS}

Ao traçar as linhas compositivas deste esquema visual, percebe-se uma grande preocupação com as proporções, com a simetria e com a distribuição dos elementos compositivos. Embora em sua visualização natural (segurando-se a nota nas mãos) não seja possível comparar as suas duas faces simultaneamente, a compatibilidade e a relação entre elas, seus elementos compositivos e suas linhas construtivas é bastante rígida e precisa. Possivelmente isso seja devido ao fato de que as notas são projetadas 
para serem colocadas contra a luz, pois esta é a forma de conferir alguns de seus dispositivos de segurança.

É importante observar ainda que o processo de impressão da nota é semelhante ao de algumas gravuras, onde todas as formas da imagem são criadas a partir da acumulação de finíssimos traços. Esses traços, no entanto, devido a esta característica de proximidade tornam-se um bloco, que em determinados detalhes parece compacto e sólido, em outros cria formas difusas, facilitando a presentificação de imagens tridimensionais, através de um tipo de ilusão de ótica.

Observando a composição do texto visual a partir de suas cores, constata-se a predominância de cores quentes, em especial tons de marrom e verde-musgo. Existe uma marcante diferença de cores entre o anverso e o reverso. No reverso, existem finíssimas linhas horizontais que cruzam todo o fundo da cédula, dando a esta face um tom mais escuro e mais bege. Já no anverso, tais linhas não foram utilizadas: o fundo da cédula nesta face é a cor do próprio papel em que ela foi impressa. Além das duas cores citadas anteriormente, existe a presença do amarelo, em pequena quantidade e sem muito destaque. No reverso da cédula, a gama de tons de verde e marrom é muito maior. Uma das causas desse efeito é a presença não apenas das linhas horizontais já mencionadas, mas também de uma série de linhas sinuosas, que variam entre as cores, causando um efeito de dégradé.

A barra texturizada do anverso, onde consta o número 1000 e as palavras Banco Central do Brasil é mais destacada, justamente pelo contraste entre suas cores e o fundo, com a cor do papel. Sua forma é bem contornada, mostrando uma clara delimitação do espaço e da relação figura e fundo. Já no reverso, tal barra é bastante diferente. Ela é muito apresenta limites muito mais suaves, embora presentes. A barra do reverso também é composta de verde e marrom, mas a relação figura e fundo não se faz tão marcante.

No reverso cabe destacar, ainda, a personificação de algum tipo de equipamento mecânico, aparentemente equipado com engrenagens e lentes. Mas não há menção a esse aparelho, nenhuma informação quanto à origem, época, autor, nacionalidade ou função. A partir do que se pode deduzir baseado no fato da nota trabalhar com dois eixos simétricos, tal aparelho está reproduzido de forma espelhada, não correspondendo a sua aparência real, enquanto objeto. 
Os textos verbais que fazem parte da composição são bastante reduzidos. No anverso, apenas o número mil em algarismos (repetido quatro vezes), a palavra "Banco Central do Brasil" (repetida duas vezes) e a legenda da efígie, onde consta "Barão de Rio Branco" (igualmente repetida duas vezes). É somente no reverso que se encontra a

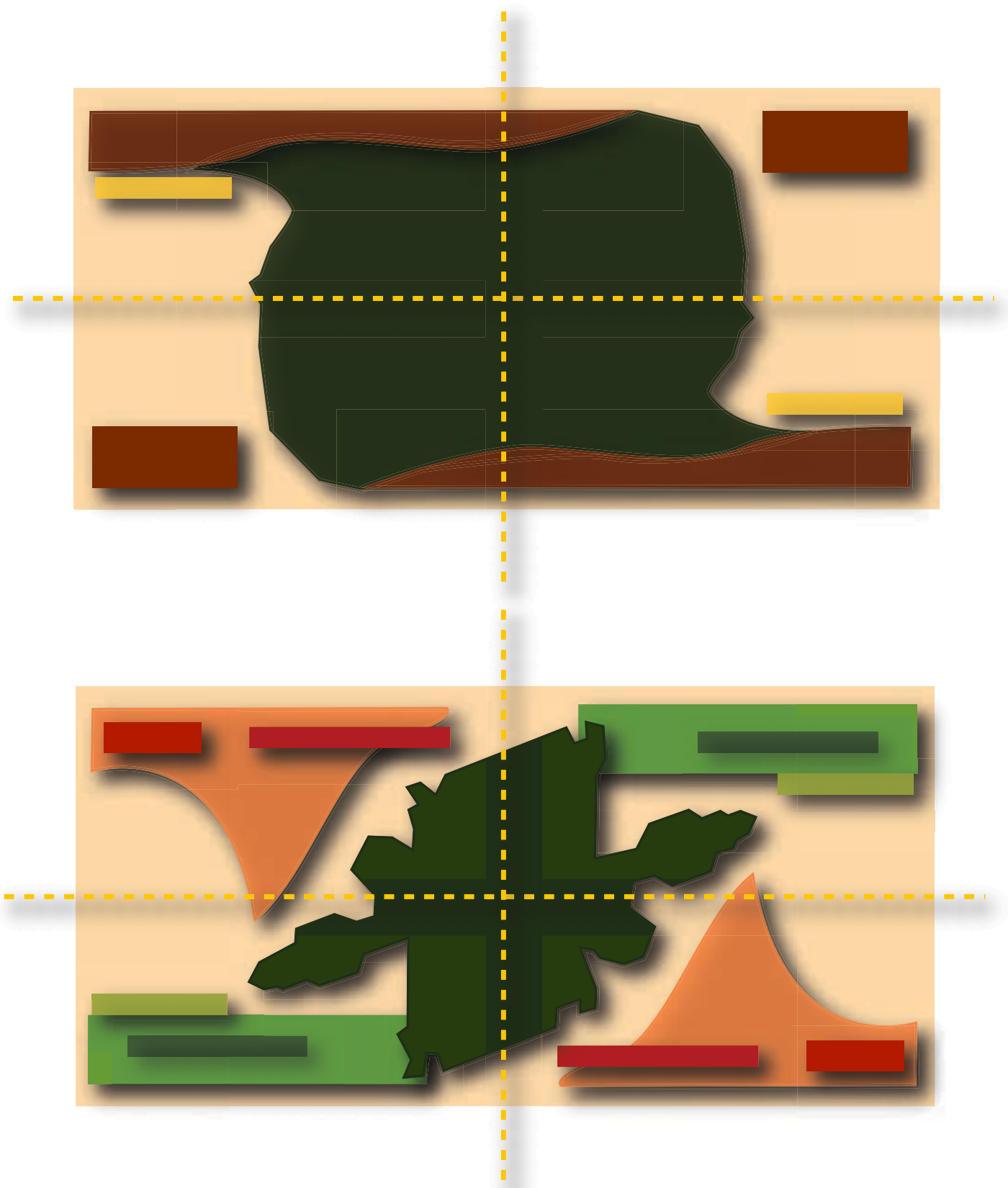

Figura 4: Mais esquemas visuais, baseados na cor e na distribuição espacial

menção à moeda: lá aparece a inscrição "mil cruzeiros" (duas vezes). Além disso, o número mil aparece em algarismos (duas vezes), também duas vezes estão impressos os números de série da cédula e a assinatura do presidente do Banco Central do Brasil. 
No esquema apresentado na Figura 4, pode-se ver, de modo geral, a relação entre cores utilizadas e as áreas onde elas se fazem presentes. Além disso, estão demarcados os dois eixos centrais de simetria, horizontal e vertical. O contraste entre cores, elementos e fundo é maior no anverso da nota, onde as áreas de cores são muito mais facilmente demarcáveis, ao passo que no reverso, essas cores são mais suaves e difusas.

Com os eixos demarcados por linhas pontilhadas, torna-se ainda mais evidente a preocupação compositiva com a simetria e seu compromisso com o equilíbrio entre formas, cores e espaço.

O layout do anverso da nota é sensivelmente mais limpo, com mais contraste e mais áreas delimitadas claramente. O reverso foi reservado para a inserção de elementos obrigatórios da cédula (número de série, nome do dinheiro, assinatura do responsável). Assim para que a composição pudesse incluir todos esses elementos, tratou-se de torna-la menos contrastada e mais homogênea, com pouca rigidez de limites entre as formas e cores.

Munido de seus sentidos e de sua capacidade cognitiva, segue o leitor na direção do desvelamento de novos conhecimentos, através de renovadas significações que encontra, transitando das partes para o todo e do conjunto do texto estético para seus componentes. (RAMALHO E OLIVEIRA, 2006, p. 217)

A análise realizada até este momento mapeou os mais diversos elementos constitutivos, possibilitando, a partir deste mapeamento, o trânsito entre as partes e o todo, exercício que leva, o leitor a encontrar novas significações, reconstruindo os efeitos de sentido.

\section{RECONSTRUÇÃO DOS EFEITOS DE SENTIDO}

Conforme Ramalho e Oliveira (2006, p. 214), "a significação, em cada texto imagético, é resultante da conjugação de dois planos que se estruturam de maneira interdependente." Esses planos são: o Plano de Expressão e o Plano de Conteúdo. Segundo Hjemslev (1991) apud Ramalho e Oliveira (2006, p. 214): "o plano de expressão, onde os elementos constitutivos ou diferenciais selecionam e articulam, ou 
seja, relacionam, relacionando-se, as qualidades que um código se utiliza para se manifestar; o plano de conteúdo, onde a significação nasce das articulações entre estes elementos diferenciais".

\begin{abstract}
Até aqui a análise se situa no âmbito do plano de expressão, pois se tratou dos elementos constitutivos, 'detectando-os'; no entanto é necessário avançar, verificando como esses elementos se organizam, se combinam ou contrastam, pois é dessas relações que nascem as significações ou os efeitos de sentido. (RAMALHO E OLIVEIRA, 2006, p. 215)
\end{abstract}

Assim, pode-se concluir que, possivelmente, em função da simetria apresentada em ambas as faces - reverso e anverso - baseada em dois eixos básicos (horizontal e vertical), emerge neste texto visual, sua forte ligação conceitual com uma carta de baralho. Em ambos os casos, a efígie presente do anverso se apresenta duplicada, formando imagens justapostas, separadas por um eixo de simetria que serve como divisor das imagens, mas também como referencia visual para o ponto central do texto visual. Apesar de largamente utilizado na confecção de baralhos, em cédulas de dinheiro este recurso não é comum tanto nos dias de hoje, quanto nas épocas em que o dinheiro corrente no Brasil era o Cruzeiro.

A partir deste eixo (e no caso da cédula são dois, em diferentes sentidos: horizontal e vertical) é que se distribuem, de forma equilibrada, todos os elementos que compõem o texto visual. Através do efeito moiré ${ }^{2}$, criam-se texturas e desenhos abstratos, ao longo de toda a superfície da cédula, em suas duas faces. Possivelmente com a função de dificultar um eventual processo de falsificação, tais desenhos apresentam, ainda, ao leitor ou enunciatário da imagem, a função decorativa, agregando harmonia e equilíbrio na composição.

Outro fator que se destaca é o uso de linhas muito finais - em alguns momentos, quase imperceptíveis - para a criação de cores e dégradés. A delicadeza criada pelo uso destas linhas atribui ao projeto gráfico leveza e sofisticação.

No anverso, destaca-se a efígie do Barão de Rio Branco. Com uma expressão suave e aparentando tranquilidade, passa-se a ideia de uma autoridade de personalidade sóbria, equilibrada e conciliadora. O uso de um forte contraste entre a

\footnotetext{
${ }^{2}$ Efeito óptico produzido pela superposição de duas ou mais retículas, caracterizado por variadas formas geométricas, agradáveis ou não. Na reprodução a várias cores (bicromia, tricomia, policromia) procura-se reduzir esse efeito, colocando-se as retículas em um determinada inclinação para cada cor, de forma que os pontos não se misturem na impressão. (RACHAÇA \& BARBOSA, 1978, p. 314)
} 
imagem do rosto do Barão e o fundo transmite uma ideia de determinação, apresentando-o como uma pessoa marcante, destacada. A barra horizontal bicolor presente nas extremidades superior e inferior do anverso transmitem solidez e tradição. A moldura sólida e marcante delimita a efígie, mas também atribui segurança e força à composição, características desejáveis quando se pensa em uma nota de dinheiro, por exemplo.

No seu reverso, a nota apresenta linhas sinuosas que presentificam um mapa cartográfico, com suas curvas de nível. Tais documentos são utilizados pela topografia para presentificar os diferentes níveis de altitude de determinado terreno, servindo como referência para a navegação em terrenos pouco conhecidos ou em que se deseja realizar algum tipo de intervenção humana.

São justamente as curvas do mapa cartográfico que dão a pista para que tipo de aparelho está presentificado no centro desta face. O aparelho é, na verdade, um espelhamento de um teodolito. O teodolito é um instrumento óptico de medida, utilizado pelos profissionais da topografia para realizar medidas e criar tais mapas. Desta forma, é perfeitamente possível deduzir que a topografia ou alguma de suas atividades correlatas tenha algum tipo de ligação forte com o Barão de Rio Branco.

Tanto o mapa topográfico, quanto o teodolito, estão integrados à composição de uma forma muito mais suave e menos contrastante do que a efígie no anverso. Isso faz com que a cédula tenha uma grande diferença em termos visuais entre suas duas faces: enquanto seu anverso é limpo, simples e contrastado, apresentando cores mais fortes e evidentes, em contraposição ao bege claro do papel moeda, seu reverso é denso, complexo e difuso, onde há a profusão de diversos elementos visuais e tons de cor.

Tendo lido a nota em seu aspecto formal e os decorrentes efeitos de sentido, com base nestes procedimentos, faz-se necessário o último passo sugerido por RAMALHO E OLIVEIRA (2006) para uma leitura de imagem: a busca dos dados de identificação da imagem.

Apresentar-se-á, a seguir, uma pesquisa que teve como objeto o autor do projeto gráfico desta cédula, bem como uma breve contextualização histórica e social, com o intuito de complementar a leitura deste texto visual. Cabe lembrar que esta identificação da imagem não foi feita de início, neste processo de leitura, em função do que a própria autora sugere. 
Os dados de identificação da imagem podem, é claro, consistir no primeiro item a ser objetivado quando de um estudo. Todavia, dados empíricos têm demonstrado que esses dados "contagiam" a análise, como que tomando do leitor a sua própria capacidade de compreender as formas e cores diante de si. (RAMALHO E OLIVEIRA, 2006, p. 218)

Embora seja bastante relevante, a identificação da imagem poderia, de fato, influenciar a análise do leitor, considerando o contexto em que a obra e autor estão inseridos. Para garantir uma leitura mais espontânea somente a partir deste momento é que se fará tal identificação.

\section{ALOÍSIO MAGALHÃES, O DESIGN VISUAL MODERNO NO BRASIL E A NOTA DO BARÃO}

O autor do projeto original, designer que concebeu a nota de mil cruzeiros se chama Aloísio Sérgio de Magalhães. Conhecido simplesmente como Aloísio Magalhães, nasceu em Recife, no dia 5 de novembro de 1927, e faleceu em Pádua, na Itália, em 13 de junho de 1982, aos 54 anos de idade. Apesar possuir bastante transito no meio artístico, optou pela faculdade de direito, onde ingressou em 1946.

Segundo o próprio Aloísio Magalhães (TABORDA \& LEITE, 2003, p. 27), "quem é que não fazia direito naquela época? Era o primeiro sinal de bom senso, quer dizer, bom senso de desejo de uma projeção política, intelectual...". A faculdade de Direito reforçou ainda mais sua formação humanística, o que teve claros desdobramentos em sua obra como designer visual, posteriormente.

Uma das características de Aloísio, desde cedo, é que em seus trabalhos, ele mesclava a sofisticação intelectual e a manifestação popular, a qual sempre lhe foi muito cara. Teve uma passagem pela Europa, em 1951, como bolsista do governo francês, em artes visuais. Voltou para Recife em 1953, sem ter conseguido encontrar o que procurava. Segundo ele, gostaria de ter encontrado "mestres que me ensinassem o que não sei. Pensei que poderia trabalhar com alguns dos pintores que admiro, porém 
não foi possível. Inclusive no que diz respeito àqueles que, como Léger $^{3}$ ou Lhote ${ }^{4}$, têm academia, não ensinam como eu entendo".

A verdadeira virada em sua trajetória como artista e designer veio no ano de 1956. Aloísio vai para a América do Norte, com uma bolsa de estudos do Departamento de Estado dos Estados Unidos da América. Lá faz algumas exposições e conhece Eugene Feldman, um artista gráfico e impressor que the apresenta novas técnicas e tecnologias como, por exemplo, a impressão em off-set.

Durante os dois meses que passou na Filadélfia, Aloísio observou, criou e refletiu muito a respeito de seu trabalho. "A cada momento, o meu pensamento voava até aqui e eu comparava e estabelecia paralelos entre o que via e o que poderia ser feito no Brasil", disse ele, certa vez.

De repente, aquele moço extremamente requintado, artista refinadíssimo, de formação humanística e pendores cosmopolitas, em dia com as vanguardas mais iniciáticas, de gosto apurado até demais, pintor aclamado do país e a caminho do reconhecimento internacional; de repente aquele moço esguio, inquieto, viajante compulsivo, a transitar com desembaraço por todas as latitudes geográficas e espirituais (e por isso mesmo parecendo às vezes à beira do diletantismo e da gratuidade), abandona essa região fluida e rarefeita da disponibilidade e se faz designer. (MELO, 1997, p. 31)

Desta vez, de volta à Recife, traz a ideia da tecnologia como possibilidade de uma nova prática e o que ela proporciona ao tempo da criação. Nos Estados Unidos finalmente compreendeu a tecnologia como aliada na economia de tempo e recursos. Passou a compreender a importância dos processos industriais e, porque não, do próprio desenho industrial - ou como se diz nos dias de hoje - design.

Pode-se afirmar que este é o começo da transição do Aloísio artista para o Aloísio designer. Tanto que em 1960, fundou o escritório $\mathrm{M}+\mathrm{N}+\mathrm{P}$, em conjunto com os sócios Luiz Fernando Noronha e Artur Lício Pontual. O M+N+P transformou-se, posteriormente, em AMPVDI (Aloísio Magalhães Programação Visual Desenho Industrial) e, então, no atual PVDI - Programação Visual Desenho Industrial. Junto com seus novos sócios Joaquim Redig e Rafael Rodrigues, projetou a identidade visual da

\footnotetext{
${ }^{3}$ Léger, Fernand (1881-1955). Pintor francês. [...] A influência de Léger sobre os artistas da época foi abrangente e diversificada. Há um museu com seu nome em Biot, na França. (CHILVENS, 2001, p. 299)

${ }^{4}$ Lhote, André (1885-1962). Pintor, escultor e teórico da arte francês. [...] Exerceu ampla influência sobre artistas mais jovens, tanto franceses como estrangeiros, através de sua própria academia de arte, a Académie Montparnasse, inaugurada em 1922. (CHILVENS, 2001, p. 306)
} 
Petrobrás, primeiro projeto de grandes proporções. Em 1965, foi responsável pela criação do primeiro símbolo da TV Globo - uma estrela de quatro pontas.

Aloísio foi, ainda, o único designer que não era funcionário de carreira da Casa da Moeda do Brasil a projetar notas de dinheiro para a instituição. Talvez, por isso mesmo, ele tenha conseguido encontrar algumas soluções e alternativas até então inéditas ou impensáveis para a época, inclusive em termos de segurança para evitar as falsificações. Antes mesmo de trabalhar no projeto da cédula de mil cruzeiros, Aloísio já havia mudado a história do dinheiro no Brasil.

Em 1966, através de um concurso fechado para artistas gráficos, Magalhães foi escolhido para iniciar o processo de nacionalização da produção de dinheiro no Brasil. O primeiro passo estava dado e, pela primeira vez, as notas brasileiras tinham, igualmente, um desenho brasileiro.

Uma importante inovação surgida do processo criativo de Aloísio foi a utilização do chamado efeito moiré. Tido como um defeito de impressão, resultado de um acidente visual entre as retículas que formam as cores, o moiré foi utilizado como gerador de padrões que dificultariam a reprodução ilegal das notas brasileiras.

De posse de um pequeno artefato formado por pequenos quadrados de filme transparente e papel onde se encontravam impressos padrões lineares similares, Aloísio percebeu que o desenho gerado por esse tipo de superposição já era em si um empecilho ao desenvolvimento de falsificações. Reproduzir um moiré provocado com exatidão se tornava quase impossível, ao menos, economicamente inviável. (TABORDA \& LEITE, 2003, p. 193)
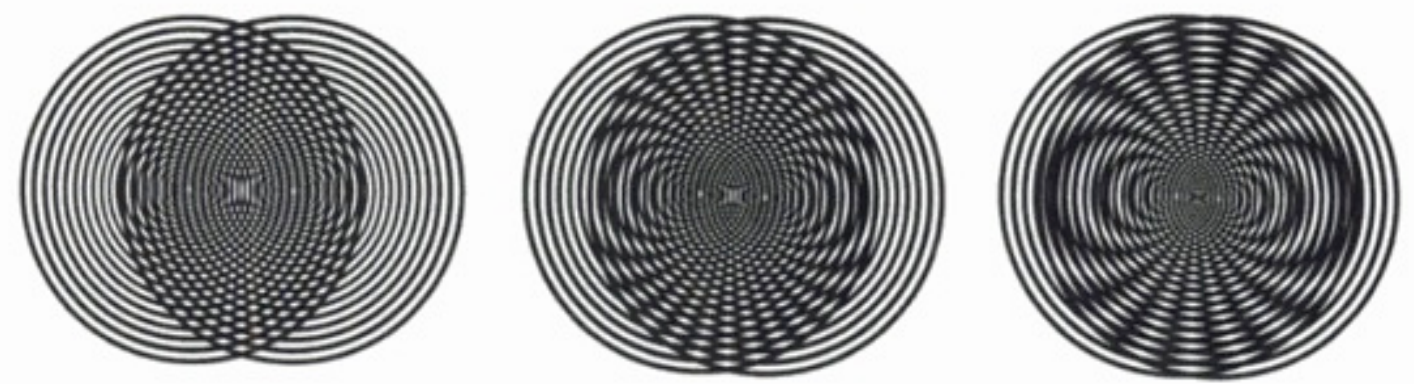

Figura 5: Exemplo das possibilidades de moiré a partir de duas retículas circulares (TABORDA \& LEITE, 2003, p. 193) 
E assim, através das ideias e projetos de Aloísio Magalhães, o país entrou em uma nova era em se tratando da impressão de seu próprio dinheiro. As novas diretrizes buscavam, acima de tudo, nacionalizar o sistema financeiro brasileiro - em especial seu processo de produção e sua parte visual, que até então seguia padrões estéticos e projetivos estrangeiros, apenas reproduzidos aqui sem nenhuma intervenção críticoreflexiva que levasse em conta a cultura local.

\section{CONSIDERAÇÕES SOBRE A CÉDULA}

Em virtude de instabilidade financeira que dominou o Brasil durante décadas e que fazia com que as houvesse grande troca de modelos de cédula, em função da necessidade de atualizar o sistema fiduciário aos efêmeros padrões de nomenclatura e valores, a nota de mil cruzeiros, objeto deste estudo, já deixou de circular há muitos anos. A cédula de mil cruzeiros, lançada em 1977, marcou o que podemos chamar de um novo padrão monetário nacional. O projeto foi concebido por Aloísio Magalhães e desenvolvido por seus colegas (e discípulos) João de Souza Leite e Washington Dias Lessa.

A nova nota trazia a efígie do Barão de Rio Branco, José Maria da Silva Paranhos Júnior, famoso pela resolução de conflitos territoriais internacionais. Aloísio dividiu o trabalho em três planos: técnico, comunicação e design. O projeto gráfico apresentou, no plano do design, uma série de inovações. A principal delas foi batizada de princípio formal do espelhamento, onde a cédula era dividida pela metade, e cada parte dessa divisão era o perfeito espelhamento da outra.

Em reunião no Banco Central, no Rio de Janeiro, presentes diretores do Banco e da Casa da Moeda, Aloísio traçou no quadro negro um programa de investigação. $O$ trabalho deveria ser desenvolvido em três planos simultâneos: o plano técnico, em que todo o conhecimento tecnológico deveria ser identificado em seu estado-daarte; o plano da comunicação, em que uma pesquisa indicaria possibilidades temáticas, e suas representações iconográficas, para o desenvolvimento do novo padrão, por fim, o plano do design, em que as informações tecnológicas deveriam ser interpretadas à luz das possibilidades de desenho que, em seu resultado, constituiriam um padrão adequado e com personalidade própria, a pautar não somente o desenho das cédulas a ser elaborado naquele exato momento, como também desenhos futuros. (TABORDA \& LEITE, 2003, p. 218) 
Com relação ao plano técnico, é importante lembrar que o projeto sofreu severas críticas com relação à segurança. Com um cédula espelhada, reduz-se em cinquenta por cento a área de segurança e, consequentemente, a dificuldade imposta aos falsificadores para executarem seu trabalho. Isso, no entanto, não impediu que o projeto gráfico fosse levado adiante. Prova disso é que a composição baseada no espelhamento da efígie foi utilizada em muitos outros projetos, posteriores, da Casa da Moeda e do Banco do Brasil, mesmo sem a presença de Aloísio como projetista.

\title{
7. CARTEMAS
}

Uma forte influência no projeto gráfico da nota de mil cruzeiros, foram os cartemas, outro importante trabalho desenvolvido por Aloísio Magalhães ao longo de sua carreira como designer. O termo "cartema" é um neologismo criado pelo filólogo Antônio Houaiss para designar este trabalho, que consistia em uma composição visual construída a partir de várias cópias de determinada imagem, tendo como suporte, a técnica da colagem.

\begin{abstract}
Por algum tempo, achei que a pintura estava morta. Hoje não posso dizer mais a mesma coisa. O desenho industrial me obrigou a ser mais pragmático, a ter um contato mais direto com o meu meio social, a aceitar muitos limites. Hoje, quando faço os cartemas, eu ainda estou aceitando um limite: o do cartão-postal. Mas, assim como não acredito que a pintura esteja morta, não coloco abaixo de nada do que faço minhas atividades como desenhista industrial. Acabei descobrindo que a cultura não é eliminatória, mas somatória. (MAGALHÃES, 1974 apud FUNARTE, 1982, p. 9)
\end{abstract}

Tais imagens eram, quase sempre, cartões postais convencionais, com retratos de paisagens diversas. Os postais eram colados lado a lado, em posições diferentes, dando ao conjunto uma nova unidade visual, face à continuidade das imagens montadas repetidamente em módulos simétricos, fortemente baseada na padronagem criada por esta composição vista como um todo. 

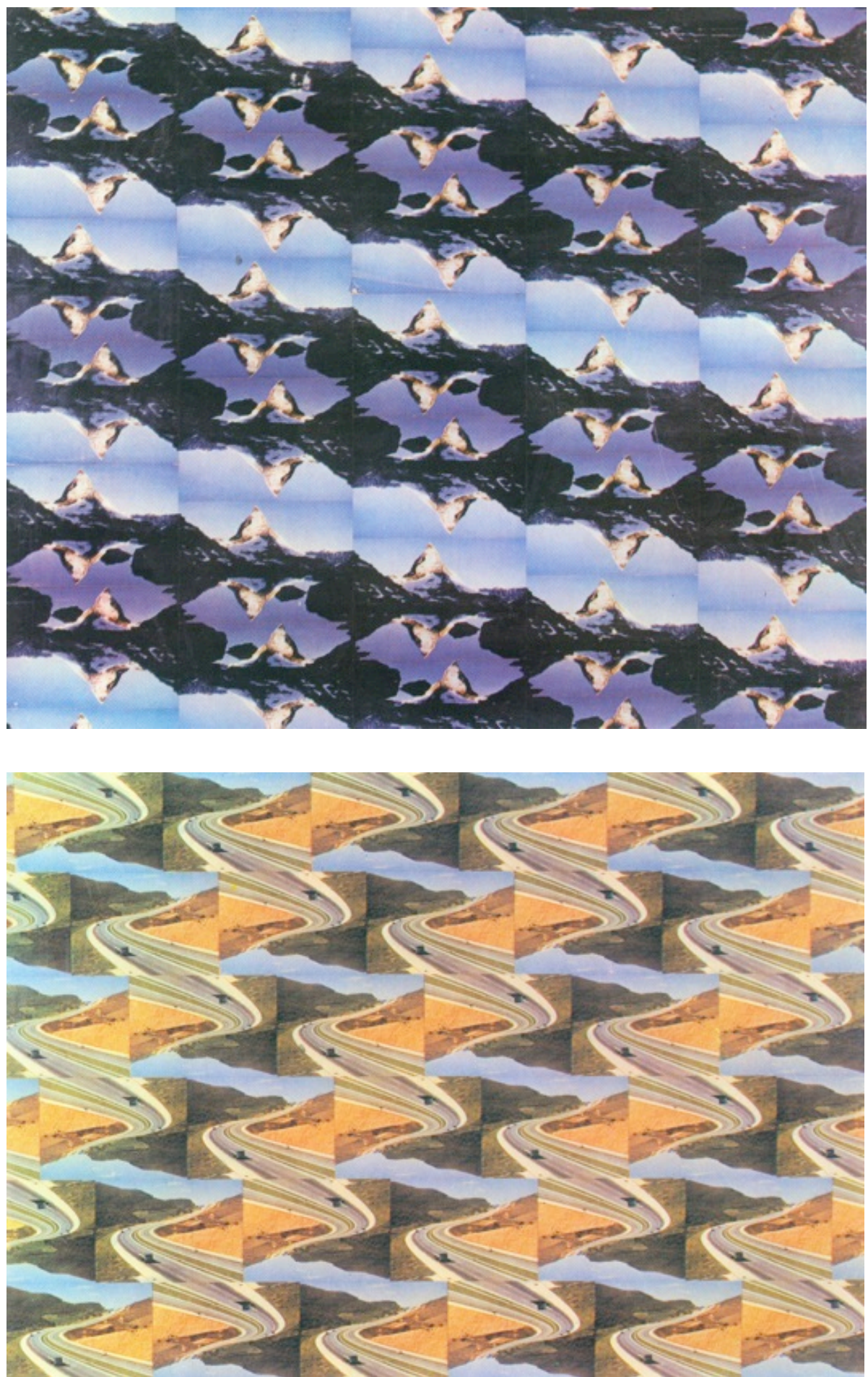

Figuras 5 e 6: Exemplos de cartemas produzidos por Aloísio Magalhães

MAGALHÃES (1973) apud FUNARTE (1982, p. 9) afirmava ainda, que "embora simples, o cartema não é um achado. Tem toda a vivência e o treinamento de um olho atento a tudo [...] A arte anda meio trágica, densa, sufocada. Perde diariamente $\mathrm{o}$ 
caráter lúdico e a graça. O cartema restitui ao espectador a alegria perdida. Ninguém fica indiferente."

O elemento (qualquer e mesmo cartão-postal) é concebido como cédula generatriz do cartema: ei-los, os cartemos de Aloísio Magalhães, poemas visuais, múltiplos rigorosamente (artesanal ou industrialmente). (HOUAISS apud FUNARTE, 1982, p. 13)

O princípio de justapor imagens, em posições invertidas foi fundamental para a concepção do projeto gráfico da nota de mil cruzeiros, uma vez que o espelhamento das imagens surge como linha central daquela que foi a marcante reformulação de todos os parâmetros do padrão monetário nacional e que, como princípio compositivo em si, mesmo depois do afastamento de Aloísio da criação das cédulas de dinheiro brasileiras, perdurou por diversas gerações de novas notas lançadas pelo Banco Central.

\section{CONSIDERAÇÕES FINAIS}

Com atuação em variadas frentes, o design visual, ou design gráfico, em sua eterna preocupação com a comunicação, apresenta-se nos mais surpreendentes lugares e objetos. Avaliar um projeto de cédula de dinheiro ainda é uma ação restrita aos designers e pesquisadores da área. No entanto, a realização deste trabalho de leitura de imagem nos mostra o quão importante é um projeto nesta área de atuação, assim como são marcantes seus desdobramentos e consequências.

Talvez o trabalho de Magalhães com projetos de cédulas não tenha sido sua melhor criação, nem tampouco a mais representativa. Mas podemos afirmar de que, juntamente com algumas de suas concepções para identidades visuais (PETROBRÁS, Light, Fundação Bienal de São Paulo) foi um dos que mais se popularizou. Assim sendo, recomenda-se ao leitor, a busca por mais informações e detalhes da história deste projeto, seu idealizador e suas origens, uma vez que ele está diretamente relacionado a história pregressa do design visual brasileiro.

Quem também se notabilizou [...] pelo seu trabalho na área de identidade corporativa foi Aloísio Magalhães, muito provavelmente o mais influente designer brasileiro do século 20. (DENIS, 2000, p. 166) 
Para se ter uma ideia da importância e do peso de Aloísio Magalhães na história do design moderno brasileiro, foi o seu aniversário, dia 5 de novembro, a data escolhida pelo Brasil, desde 1998, para comemorar o Dia Nacional do Design ${ }^{5}$.

\begin{abstract}
A partir de sua notável atuação como designer [...] Aloísio deslanchou no final da década de 1970 para uma carreira como dirigente cultural, tornando-se fundador e coordenador do Centro Nacional de Referência Cultural em 1976, diretor-geral do Instituto do Patrimônio Histórico e Artístico Nacional (IPHAN) em 1979 e fundador e presidente da Fundação Nacional Pró-Memória em 1980. Ao ampliar o enfoque do seu trabalho para a política cultural, Aloísio traduziu para um plano maior as possibilidades de atuação do designer no Brasil, demonstrando através de sua prática que é possível projetar não somente os objetos materiais que definem um contexto cultural, mas também a própria identidade que se constrói a partir deles. (DENIS, 2000, p. 199)
\end{abstract}

Aloísio, desde muito jovem, entendeu que a importância do design não se restringia ao processo de projeto. Foi um dos primeiros profissionais da área a utilizar o desenho industrial como ferramenta de transformação social e cultural, além de ter sido um grande pesquisador e promotor da cultura brasileira.

O chamado processo de desenvolvimento de uma cultura não se mede somente pelo progresso e pelo enriquecimento econômico, mas por um conjunto mais amplo e sutil de valores. [...] só através da análise e de estudos interdisciplinares, se poderá alcançar a compreensão do conjunto de fatores que serão capazes de configurar um crescimento verdadeiramente harmonioso. Aos fatores econômicos [...] foram acrescentados os fatores sociais e, já agora, a compreensão do todo cultural. O Desenho Industrial surge [...] como uma disciplina capaz de se responsabilizar por uma parte significativa deste processo. Porque não dispondo nem detendo um saber próprio, utiliza vários saberes que se ocupam da racionalização e da medida exata - os que dizem respeito à ciência e à tecnologia - $\mathrm{e}$ de outro, daqueles que auscultam a vocação e a aspiração dos indivíduos - os que compõem o conjunto das ciências humanas. (MAGALHÃES, 1998, p. 12)

Mais especificamente, no que diz respeito à nota do Barão, dentro de seu contexto, não apenas como obra de Aloísio, mas como bem cultural nacional, é possível afirmar que foi uma verdadeira quebra de paradigma da relação entre dinheiro e cultura. Um dos principais indícios desta influência no cotidiano do povo brasileiro é o fato de

\footnotetext{
${ }^{5}$ Decreto presidencial 7508, de 19 de outubro de 1998, que institui o "Dia Nacional do Design" e dá outras providencias. Acessível, na íntegra, no site da Presidência da República, em http://www.planalto.gov.br/ccivil_03/dnn/Anterior\%20a\%202000/1998/Dnn7508.htm
} 
que a palavra "Barão" (clara referência a efígie da nota) é utilizada até hoje para a quantidade "mil", quando se fala em dinheiro no Brasil.

\section{REFERÊNCIAS BIBLIOGRÁFICAS}

CHILVENS, I. Dicionário Oxford de Arte. 2ª . Ed. São Paulo: Martins Fontes, 2001.

DENIS, R. C. Uma introdução à história do design. São Paulo: Edgard Blücher, 2000.

FUNARTE. Cartemas: A Fotografia como Suporte de Criação. Rio de Janeiro:

Fundação Nacional de Arte/Núcleo de Fotografia. 1982.

MAGALHÃES, A. O Que o Desenho Industrial Pode Fazer pelo País? In: Arcos:

Design, Cultura Material e Visualidade, Rio de Janeiro: ESDI, 1998, v. I, n. único, p. 813.

. E Triunfo? A Questão dos Bens Culturais no Brasil. Rio de Janeiro: Nova Fronteira; Fundação Roberto Marinho, 1997.

MELO, J. L.. Lembrança do amigo. In: MAGALHÃES, A.. E Triunfo? A Questão dos Bens Culturais no Brasil. Rio de Janeiro: Nova Fronteira; Fundação Roberto Marinho, 1997.

RACHAÇA, C. A.; BARBOSA, G. Dicionário de Comunicação. Com a colaboração de Muniz Sodré. Rio de Janeiro: Ed. Codecri, 1978.

RAMALHO E OLIVEIRA, S. R.. Imagem também se lê. São Paulo: Edições Rosari, 2005.

Imagem também se lê. In: Silvia Zanatta Da Ros; Kátia Maheirie; Andréa Vieira Zanella. (Org.). Relações estéticas, atividade criadora e imaginação: sujeitos e (em) experiência. 1ed. Florianópolis: NUP/CED/UFSC, 2006, v. 11, p. 209-220.

TABORDA, Felipe; LEITE, João de Souza. A Herança do Olhar: o Design de Aloísio Magalhães. Rio de Janeiro: Artviva/SENAC. 2003. 